\title{
Linguagem em carne viva: corpo, percepção, linguagem (rumo a uma semântica aberta do gesto)
}

\section{Language in Living Flesh: Body, Perception, Language (towards an open semantics of gesture)}

\section{En carne viva, el lenguage: el cuerpo, la percepción, la lengua (hacia una semántica abierta del gesto)}

Sérgio Roclaw Basbaum

(Pontifícia Universidade Católica de São Paulo, Brasil) *

https://doi.org/10.22409/poiesis.v21i35.38644

RESUMO: O artigo documenta um percurso pedagógico original, com achados, sínteses e intuições importantes na trajetória de pesquisa. Por meio de uma abordagem transdisciplinar, marcada pelo pensamento fenomenológico, descreve-se a descoberta e formalização de uma metodologia para o estudo das relações entre corpo, percepção e linguagem, tendo como atrator uma semântica do gesto. Tomando como preceitos conceituais: a) a primazia da experiência; b) uma opção pela percepção enativa, culturalmente modulada; c) uma definição de gesto; e d) a opção por uma semântica baseada no corpo, reflexões, práticas e exercícios foram propostas, resultando na elaboração de um modelo de Glossário dos Próprios Gestos.

PALAVRAS-CHAVE: gesto; semântica; sinestesia; percepção; linguagem

\footnotetext{
* Sérgio Roclaw Basbaum é professor do Programa de Estudos Pós-Graduados em Tecnologias da Inteligência e Design Di-gital (TIDD) da Pontifícia Universidade Católica de São Paulo. E-mail: sergiobasbaum@pucsp.br. Orcid: https://orcid.org/0000-0001-5433-2578
} 
ABSTRACT: The article documents an original pedagogical path, with important findings, syntheses and intuitions in the research trajectory. Through a transdisciplinary approach, marked by phenomenological thinking, we describe the discovery and formalization of a methodology for the study of the relations between body, perception and language, keeping as its attractor a semantics of gesture. Taking as conceptual precepts: a) the primacy of experience; b) an option for enactive, culturally modulated perception; c) a definition of gesture; and d) the choice of bodybased semantics, reflections, practices and exercises were proposed, resulting in the elaboration of a Glossary of Own Gestures model.

KEYWORDS: gesture; semantics; synesthesia; perception; language

RESUMEN: El artículo documenta un camino pedagógico original, con importantes hallazgos, síntesis e intuiciones en la trayectoria de investigación. A través de un enfoque transdisciplinario, marcado por el pensamiento fenomenológico, describimos el descubrimiento y la formalización de una metodología para el estudio de las relaciones entre cuerpo, percepción y lenguaje, teniendo como atractor una semántica del gesto. Tomando como preceptos conceptuales: a) la primacía de la experiencia; b) una opción para la percepción activa, modulada culturalmente; c) una definición de gesto; y d) la elección de una semántica basada en el cuerpo, se propuso reflexiones, prácticas y ejercicios, que resultaran en la elaboración de un modelo de Glosario de Gestos Propios.

PALABRAS CLAVE: gesto; semántica; sinestesia; percepción; lenguaje 


\section{Linguagem em carne viva: corpo, percepção, linguagem (rumo a uma semântica aberta do gesto)}

\section{Introdução ${ }^{1}$}

Na Fenomenologia da Percepção, como se sabe, Merleau-Ponty, atribui importância absoluta ao papel da percepção na produção do mundo da nossa experiência:

[...] 0 mundo está ali antes de qualquer análise que eu possa fazer dele, e seria artificial fazê-lo derivar de uma série de sínteses que ligariam as sensações, depois os aspectos perspectivos do objeto, quando ambos são justamente produtos da análise e não devem ser realizados antes dela. (MERLEAUPONTY, 1994, p. 10)
Nessa perspectiva, a questão de como o mundo percebido se torna o mundo falado é inescapável. A fala leva adiante a percepção, "sem se reduzir a ela":

Essa linguagem muda ou operacional da percepção põe em movimento um processo de conhecimento que ela não é suficiente para completar. Por mais firme que seja a minha apreensão perceptiva do mundo, ela é totalmente dependente do movimento centrífugo que me lança a ele, e jamais o retomarei a menos que eu mesmo estabeleça, e espontaneamente, dimensões novas de sua significação. Aqui começa a fala, 0 estilo de conhecimento, a verdade no sentido dos lógicos. Esta é exigida, 
desde seu primeiro momento, pela evidência per-

ceptiva, e a leva adiante sem se reduzir a ela.

(MERLEAU-PONTY, 2002, p. 157)

O ensaio "Esboço de uma teoria das relações entre percepção e linguagem, sob a determinação do sentido", resultado do pós-doc realizado em 2010 sob a supervisão de Alfredo Pereira Jr., tenta formalizar um modo de pensar e um modo de falar sobre as relações entre percepção, corpo, gestos, linguagem e sentido, e contém diversas intuições que, desde então, vêm alimentando meu trabalho como pesquisador e professor. Além de Merleau-Ponty, a pesquisa, sempre transdisciplinar, buscou autores como Martin Heidegger, Marshall McLuhan, Humberto Maturana, Vilém Flusser, Guy Van de Beucque, Lawrence Marks e Ramachandran e Hubbard. O ensaio foi finalmente publicado em 2018, com pequenas revisões, no livro editado por Alexandre Quaresma (2018), Artificial Intelligences: Essays on inorganic and nonbiological systems.

Alguns anos depois, em agosto de 2015, fui alocado para a disciplina "Fundamentos da Comunicação Corporal", na graduação em Comunicação das Artes do Corpo, na PUC-
SP. Como já era início do semestre, e não havia tempo hábil para preparar um programa de curso, decidi partir da minha própria pesquisa, e isso me deu tempo para ir pensando em outros materiais e estratégias de ensino. O que se buscava realmente sobretudo pelo perfil do curso -, era encontrar meios para que os estudantes pudessem experienciar as noções e conceitos propostos. Acrescentei alguns filmes e outros artigos para fomentar a discussão e, ao final do semestre, duas bailarinas e coreógrafas, Julia Salém e Juliana Gennari (Fig. 1), com quem eu havia trabalhado em 2014 no espetáculo Instaura_ação ${ }^{2}$, me ajudaram a desenhar alguns exercícios a partir de um conceito de gesto ali proposto. Como temos vivido em perpétuo overbooking, não tive o cuidado de registrar este encontro, algo de que muito me arrependo. Mas, com um ótimo retorno dos alunos, pude desenvolver uma visão clara de como conduzir um processo de estudo sobre percepção e gesto, em uma abordagem inspirada pela filosofia de estilo fenomenológico.

Um ano mais tarde (2016), na mesma disciplina, convidei a coreógrafa e bailarina Camila Venturelli (Fig. 2) para colaborar nas práticas corporais, de modo que os alu-

Sérgio Roclaw Basbaum, Linguagem em carne viva: corpo, percepção, linguagem (rumo a uma semântica.. 


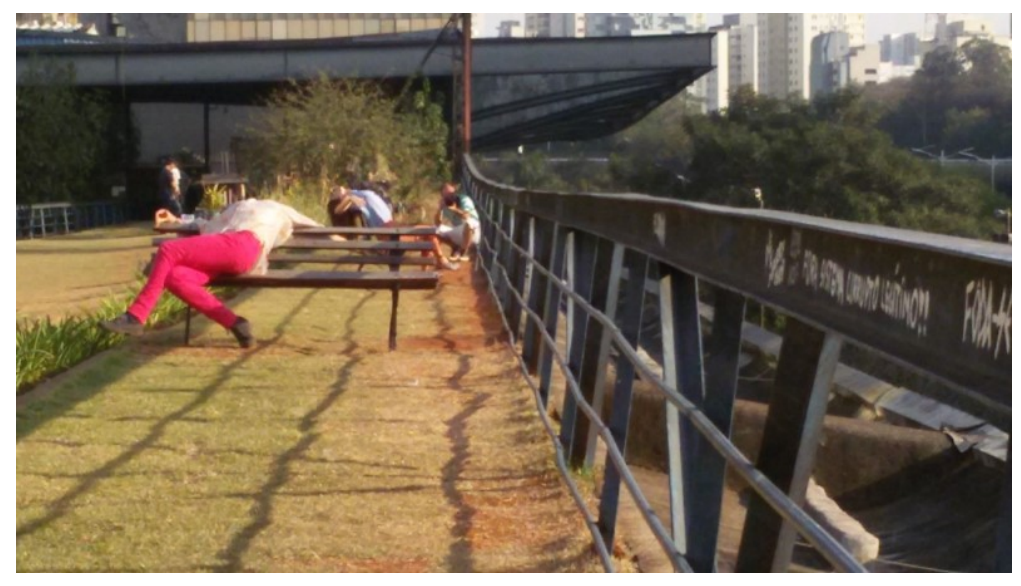

Fig. 1 - Julia Salém, Juliana Gennari, Instaura_ação (2014). (Foto: Sérqio Basbaum) 


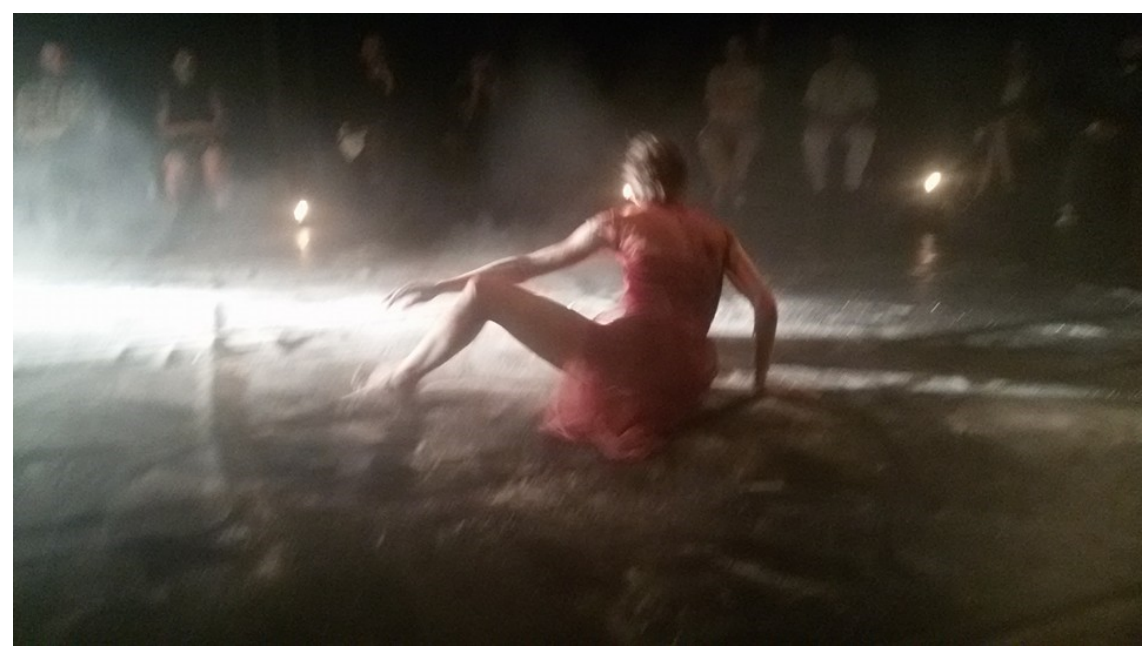

Fig. 2 - Camila Venturelli: O segredo de Lindonéia (2015).

(Foto: Séraio Basbaum, 2016)

Sérgio Roclaw Basbaum, Linguagem em carne viva: corpo, percepção, linguagem (rumo a uma semântica... 
nos pudessem experienciar os conceitos propostos. Desenhamos também um modelo de trabalho escrito individual, envolvendo as relações entre corpo, gesto, sentido e significado. Neste trabalho, a unidade dos sentidos, como base para a semântica, desempenha um papel central. Apresento aqui uma síntese reflexiva deste trajeto.

\section{Pressupostos teóricos}

O trabalho em sala de aula partiu de alguns pressupostos, menos ou mais controversos. Um conjunto de autores e definições teóricas circunscrevendo um estilo e um território de pesquisa, fundamentos para decisões coerentes no que diz respeito à relação entre os conceitos e as estratégias de ensino:

\section{a) Modelos científicos $x$ experiência}

Explicações e modelos científicos são ótimos, mas não têm como dar conta da experiência direta. Modelos não podem lidar com a dimensão incomensurável da experiência e, de modo algum, a certeza aberta que aí se conhece pode ser substituída pelas certezas reducionistas e racionalizadas da ciência. Dupuy (1996, p. 25) descreve bem a fascinação do cientista pelo modelo, dadas as facilidades que este oferece pelo modo como simplifica, ou reduz, o real. Em uma passagem especialmente inspirada, tratando das experiências de sinestetas como Michael Watson (MW), protagonista de seu livro The man who tasted shapes, Richard Cytowic (1997, p. 32, tradução nossa) comenta:

\section{Minha resposta usual àqueles que me perguntam se a sinestesia é 'real' é: 'Real para quem? Para vo- cê, ou para aqueles que a experienciam? Duvidar da realidade da sinestesia até que haja alguma comprovação tecnológica mostra o quão estamos prontos para rejeitar quaisquer experiências em primeira pessoa. Somos viciados no externo e no racional. Nossa insistência numa compreensão do mundo 'objetiva' em 'terceira-pessoa' simplesmen- te varreu para longe todas as outras formas de co- nhecimento.}

\section{b) Percepção: sentidos e sentido}

"Percepção" é uma relação ativa entre um organismo e seu ambiente, através da qual esse organismo faz o sentido do seu mundo. Ao definir "coisas" em uma relação figura-fundo, "figuras" emergem de um todo, de acordo com a intenção de um organismo em sua circunstância: ele ou ela "encena" (enacts) o seu mundo (e.g. VARELA; THOMPSON; ROSH, 1991; NOE, 2004). "Coisas" não são "objetos" e, como nos ensinou a 
escola gestaltista alemã, seu significado depende do todo do qual emergem. Aquilo a que nos referimos como "mundo", no qual experienciamos a vida, é um acordo intersubjetivo ao qual nomeamos "realidade". Em uma definição mais recente, que leva em conta a calibragem do organismo a seu mundo por meio dos ritmos do cérebro (BUZSAKI, 2011), podemos dizer que perceber é sincronizar-se com os relevos do mundo (BASBAUM, 2018b) ${ }^{3}$. E atribuir relevância $a$ isto ou àquilo é atribuir sentido ao mundo. Os sentidos são inseparáveis do sentido. (ver BASBAUM, 2017; 2018a)

\section{c) A percepção é biocultural}

Pois hoje reconhecemos que processos tais como pensar, perceber, lembrar e aprender devem ser estudados dentro dos contextos ecológicos das interrelações entre as pessoas e seus ambientes. Reconhecemos, também, que a mente e suas propriedades não são dadas antecipadamente à entrada do indivíduo no mundo social, mas antes modeladas através de uma história de vida de envolvimentos em relações com outros. Esabemos que é através destas atividades de uma mente encarnada [embodied mind] (ou corpo enmentad $0^{4}$ ) [or enminded body] que as relações sociais são formadas e reformadas. Processos psicológicos e sociais são um e o mesmo. (INGOLD, 2000, p. 171, tradução nossa)
Biologicamente circunscrita, a percepção humana é coletivamente modulada por padrões culturais. Somos entes bioculturais. $\mathrm{Na}$ cultura ocidental, a visualidade tem enorme primazia sobre os demais sentidos corporais. Há miríades de exemplos sobre isso. Seguindo uma intuição de McLuhan, a antropologia dos sentidos (CLASSEN, 1993; HOWES, 2003) afirma e reafirma a hegemonia da visualidade na cultura ocidental, essa história que nos deu uma linhagem de aparatos ópticos sem paralelo em qualquer outra cultura, sobre os quais se construiu todo um modelo de conhecimento baseado na observação empírica (BASBAUM, 2016; 2017). Impossível pensar a percepção e a cognição sem entender que o corpo, com seus limites biológicos - seus "itens de fábrica" - se realiza e se atualiza, percebe e significa dentro das possibilidades da cultura.

\section{d) Performar um gesto consuma mundo}

Ao discutir o "gesto que produz imagens", Vilém Flusser (1996, p. 64) usa os seguintes termos: "imagem é visão tornada fixa e intersubjetiva". É uma visão partilhada. Isso não vale apenas para o gesto que produz imagens, mas para qualquer gesto: um gesto é expressão, acontecimento, de um estado interior, partilhado com uma comu-

Sérgio Roclaw Basbaum, Linguagem em carne viva: corpo, percepção, linguagem (rumo a uma semântica... 
nidade. Aquilo que, nas ciências cognitivas, é o output do "ciclo percepção-ação", pode ser entendido como a exterioridade de um modo de encenar um mundo. [MerleauPonty (1994, p. 263): "o gesto dá, pela primeira vez, um sentido humano ao objeto"]. Como tal, um gesto é a afirmação de um modo de perceber; emerge da maneira pela qual um corpo dá sentido ao mundo; e afirma seu próprio modo de encenar o mundo. A construção de uma realidade partilhada, comum, intersubjetiva, depende de partilharmos nossas percepções interiores com os outros, de forma que cada gesto que performamos, a um só tempo (BASBAUM, 2018a):

- dá sentido ao mundo;

- é "tomada de posição" em relação ao mundo;

- é partilha de mundo;

- é um performar no devir.

Dado que qualquer relação figura-fundo depende de um observador, pode-se dizer, parafraseando Maturana (2002, p. 128), que o gesto aparece como tal para um observador, que pode até ser, ele mesmo, o agente do gesto.

\section{e) Então, o que é um "gesto"?}

Estamos, então, em condições de propor uma definição de "gesto":

\section{Para um agente (actante), em uma circunstância, transcendência do corpo em direção ao outro: par- tilha de mundo, tomada de posição em relaçãa ao mundo, performar no devir; para um segundo, em uma circunstância, figura-corpo sobre fundo-corpo (é 0 observador que vê o gesto como tal); para um terceiro, relação comunicativa entre dois - um primeiro e um segundo, não necessariamente nes- sa ordem; para um quarto, contexto epistemológi- co (inicialmente intraduzível pois que) fundado so- bre conhecimento tácito. (notas de curso, 2016)}

Todas essas posições - a1, a2, a3, a4, para agente 1, 2 etc... - estão bastante bem representadas nos primeiros minutos do clássico Ritual in Transfigured Time (1946), a fábula fílmica onírica de Maya Deren (Fig. 3). Deren (a1) aparece inicialmente, com sua figura sempre enigmática, enrolando entre as mãos um fio de lã, em movimentos amplos dos braços, gestos que são vistos por uma nova figura feminina (Rita Christiani, a2), que com ela se conecta, de modo que passam a trocar gestos, ligadas pela linha - uma materialização metafórica do processo de comunicação, lembrando vaga- 


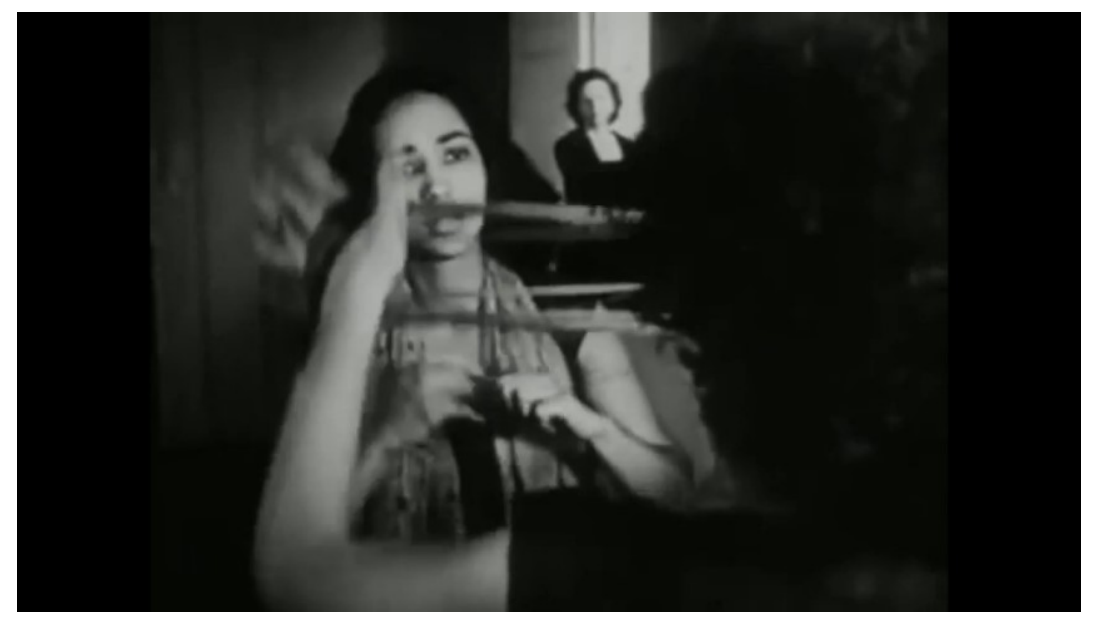

Fig. 3 - Maya Deren (de costas, à direita: a1); Rita Christiani (esquerda: a2), Anais Nin

(fundo: a3): Ritual of transfiqured time (1946). O espectador encarna a posição a4.

Sérgio Roclaw Basbaum, Linguagem em carne viva: corpo, percepção, linguagem (rumo a uma semântica... 
mente os experimentos realizados mais tarde por Lygia Clark; finalmente, outra figura (Anais Nin, a3) surge ao fundo e observa a troca de gestos entre as duas. 0 espectador (a4) contempla todo esse contexto e o interpreta a partir de seu contexto tácito.

Levando em conta essa definição e o postulado anteriormente, o gesto pode ser pensado em um eixo que vai do biológico ao cultural. Mas eles não se excluem: biológico e cultural co-modulam um ao outro.

$<$ bio $>$ $<$ cultural $>$

Assim, quando Giorgio Agamben toma o atlas Mnemosyne, de Amy Warburg, o descreve como um magnífico catálogo dos gestos humanos, registrados desde a Antiguidade: "[...] Nesse sentido, o atlas Mnemosyne, que ele deixou incompleto, com suas cerca de mil fotografias, não é um imóvel repertório de imagens, mas uma representação em movimento virtual dos gestos da humanidade ocidental, da Grécia clássica ao fascismo". (AGAMBEN, 2008, p. 11)

Interessantemente, Jean-Luc Godard, em suas Histoire(s) du Cinema, 2A: Fatale Beauté, olha suas mãos que datilografam, as compara a imagens em que as mãos têm protagonismo e conclui: "pensar com as mãos". (Fig. 4, 5 e 6)

\section{Rumo à semântica corporal de Ruthrof}

\section{a) Lingugem, gesto, iconicidade}

A fala também é um gesto: é uma potência do corpo e depende dos limites físicos do corpo. Além disso, sendo essencialmente comunicação, depende de haver mais de um indivíduo envolvido. Maturana já apontava que é preciso haver um domínio fenomênico em comum, é preciso mais de um para haver linguagem, assim como, para MerleauPonty, a linguagem é uma transcendência do corpo na direção do outro. Colocada assim, como um gesto entre outros, a linguagem é, porém, um gesto particular: nos eleva a um mundo diferente, o mundo da linguagem (oral). Mas, ao fazê-lo, traz consigo todo o corpo (MERLEAU-PONTY, 1994; MCLUHAN, 1995; FELD, 2005).

Como sabemos, a partir de diversos autores (MARKS, 1978; RAMACHANDRAN; HUBBARD, 2001), há relações icônicas entre as coisas percebidas e a linguagem. Na comunidade que pesquisa a sinestesia, são popu- 

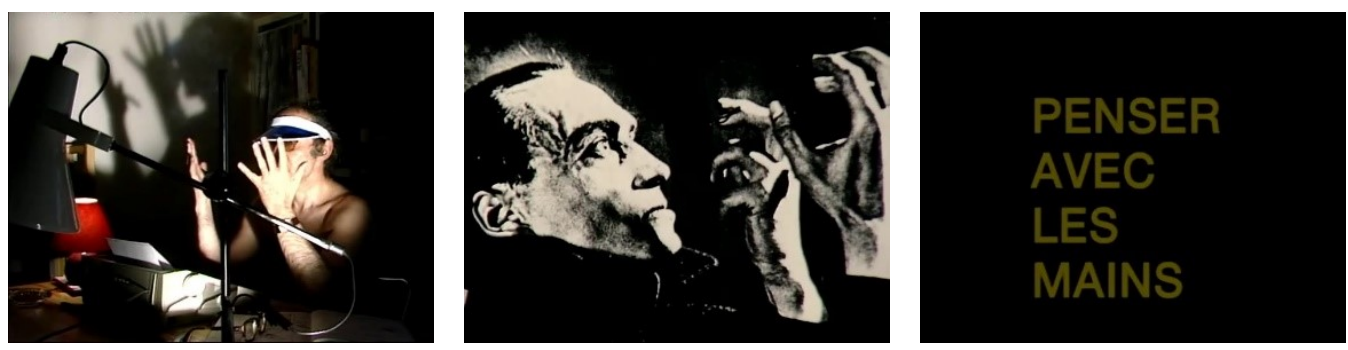

Fig. 4, 5, 6 - Jean-Luc Godard, Histoire(s) du Cinema, 2A: Fatale Beauté: pensar com as mãos. 
lares os exemplos dos efeitos "taketemaluma" (Fig. 7), ou "kiki-bouba" (Fig. 8), resultados dos experimentos de Wolgang Kohler. Marks (1978; 1997) escreveu sobre as dimensões comuns entre os diferentes sentidos; e além disso, há uma relação bastante óbvia entre a música e a dança, por exemplo.

\section{b) A semântica corporal de Ruthrof}

De acordo com a abordagem intersemiótica e heterossemiótica da semântica [...] não há significado na linguagem ou no dicionário. Ao invés, o significado verbal ocorre quando expressões linguísticas são ativadas por signos não-verbais, táteis, olfativos, gustativos, termais, hápticos, aurais, e outras leituras perceptivas. Desse modo, o significado é um evento intersemiótico e heterossemiótico, uma ligação entre sistemas sígnicos distintos. (RUTHROF, 1997, p. 254)

Assim, de acordo com o livro do semioticista alemão Horst Ruthrof, Semantics and the Body (1997), o significado emerge de todos os sentidos corporais, em uma combinação daquilo que ele nomeia processos "heterossemióticos" e "intersemióticos": cada palavra tem seu sentido definido pela maneira como se dá a sua apropriação por cada um dos sentidos corporais - heterossemiótica e pelo jogo entre os sentidos - "intersemiótica": o significado emerge do modo como um corpo biocultural se eleva à transcendência da linguagem, sem nunca perder de vista sua dimensão carnal.

\section{Práticas com os alunos}

Não é possível capturar aqui todas as sutilezas envolvidas nessa abordagem das relações entre percepção-gesto-linguagem. Mas, para experienciar as noções sintetizadas acima, e permitir aos alunos aprofundar sua capacidade de observar os próprios gestos e os gestos dos demais - de tal forma a tornar tangíveis as posições de agência propostas e examinar a alquimia que vai do corpo à linguagem -, um conjunto de exercícios foi proposto ao longo das aulas:

a) exercícios corporais nos quais os estudantes deviam propor gestos, observar gestos nos corpos dos colegas, interpretar os seus gestos e os dos outros, de muitos modos. Por exemplo, usando diferentes molduras para olhar os corpos dos colegas, enquadrando algum aspecto ou movimento especialmente interessante, nomeando-o como um "gesto" (Fig. 9 e 10). 

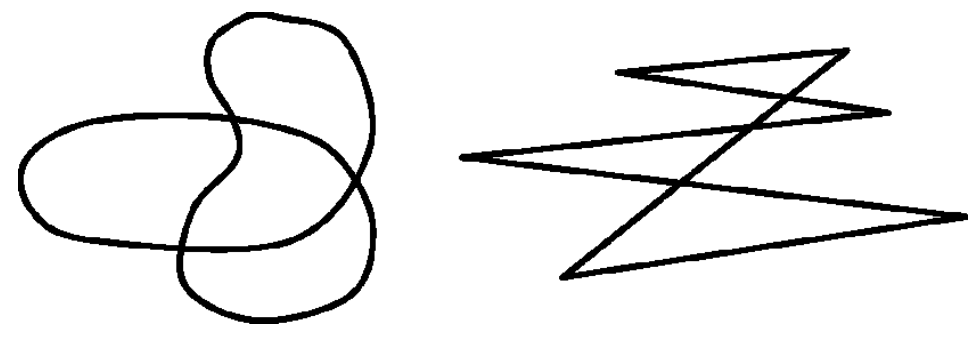

310
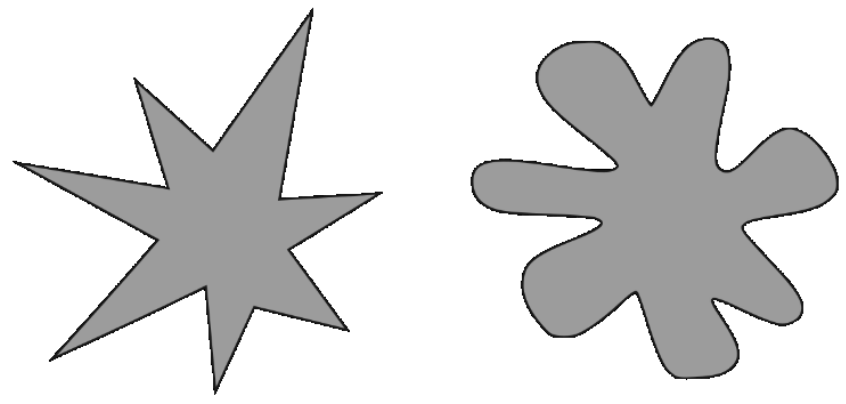

Fig. 7 - takete e maluma: figuras abstratas descritas por pseudo-palavras (Marks, 1978, a partir de Kohler)

Fiq. 8 - kiki e bouba (Ramachandran; Hubbard, 2001)

Sérgio Roclaw Basbaum, Linguagem em carne viva: corpo, percepção, linguagem (rumo a uma semântica... 

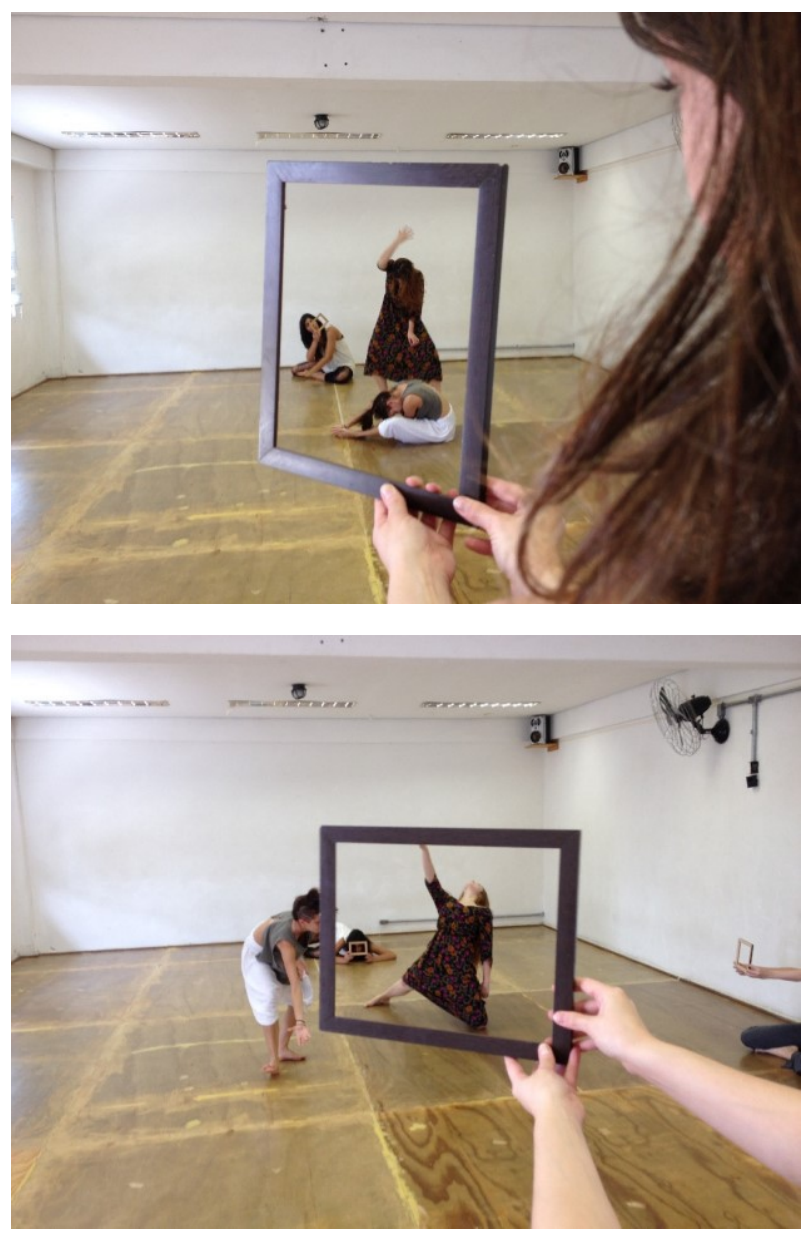

Fig. 9 e 10 - enquadramento de gesto (a) (b) (Fotos: Camila Venturelli) 
b) Utilizando jogos de cartas envolvendo a relação entre percepção e linguagem. No caso, escolhemos experimentar o popular Dixit. Este jogo, baseado na criação de relatos a partir de imagens oníricas (Fig. 11, 12 e 13), já desafia a capacidade metafórica, imaginativa e expressiva quando trabalhado no âmbito verbal, para o qual foi concebido. Trazido ao terreno ainda mais aberto do gesto, serviu como estímulo a jogos de gestos e imagens.

C) Observando os próprios gestos e propondo "pseudo-palavras" (ao estilo kikiGestos, criado a partir da mecânica de jogo do Dixit, que produziu incríveis combinações de palavras (Fig. 14).

d) Finalmente, um trabalho individual foi solicitado, no qual cada estudante deveria, partindo da definição de gesto proposta acima, descrever e nomear seus próprios gestos do seguinte modo:

1. Ao longo do curso, e partindo do recorte teórico proposto, observe os seus gestos diários;

2. Registre os gestos observados (figura-corpo sobre fundo corpo);

3. Escolha 10 de seus gestos e componha um glossário, da seguinte maneira (Fig. 15).

Como resultado, surgiram trabalhos como os que seguem (Fig. 16, 17 e 18).

Sérgio Roclaw Basbaum, Linguagem em carne viva: corpo, percepção, linguagem (rumo a uma semântica. 

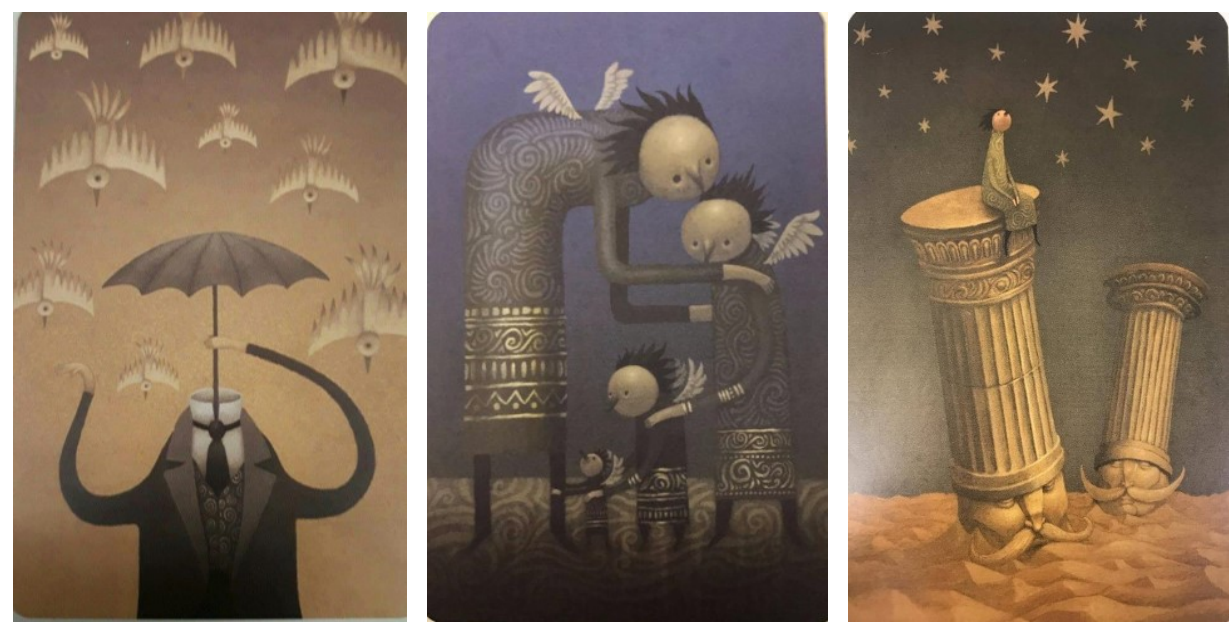

Fiq. 11,12 e 13 - as cartas oníricas do Dixit.

Poiésis, Niterói, v. 21, n. 35, p. 297-324, jan./jun. 2020. 


$\begin{array}{lllllll}\text { pleidi } & \text { tlaves } & \text { árhem } & \text { correneo } & \text { tompa } & \text { respaul } & \text { vram } \\ \text { krumpl } & \text { flinkt } & \text { necanê } & \text { unka } & \text { strax } & \text { quart } & \text { nombu } \\ \text { trak } & \text { tampi } & \text { nalioba } & \text { caliá } & \text { tuiim } & \text { filiti } & \text { vleumn } \\ \text { toróqui } & \text { pumiê } & \text { patú } & \text { miun } & \text { eslire } & \text { duk } & \text { umgu } \\ \text { pranpk } & \text { kunf } & \text { pontála } & \text { omun } & \text { kúncio } & \text { zanestar } & \text { ditálo } \\ \text { flansh } & \text { tanon } & \text { lash } & \text { sintálamo } & \text { yum } & \text { sperax } & \text { ripit } \\ \text { crak } & \text { dulin } & \text { kamam } & \text { chúcia } & \text { ponik } & \text { okunu } & \text { pitaiê } \\ \text { tamasi } & \text { vibisso } & & & \text { pitôcu } & \text { zirin } & \text { vírict } \\ \text { pruc } & \text { kriks } & & & & & \text { nâmnia }\end{array}$




\section{GLOSSÁRIO DOS MEUS PRÓPRIOS GESTOS}

\section{Foto do seu gesto}

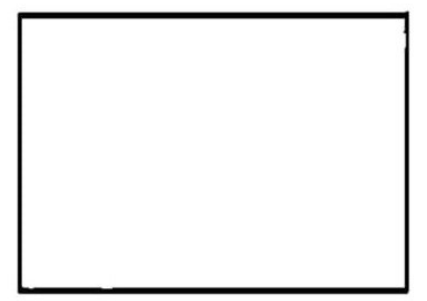

Nome do gesto

(pseudo-palavra)

\begin{tabular}{|c|c|c|c|c|}
\hline a. & b. & c. & d. & e. \\
\hline o que eu faço? & o que eu sinto (1) & o que eu sinto (2) & a linha do gesto & cor \\
\hline $\begin{array}{l}\text { Descrição do gesto } \\
\text { o mais objetiva } \\
\text { possível: o trabalho } \\
\text { do observador. } \\
\text { De }(\text {...) > (...) Para } \\
\text { (movimento) }\end{array}$ & $\begin{array}{l}\text { A fisicalidade do } \\
\text { gesto vista de } \\
\text { dentro, em primeira } \\
\text { pessoa. Por ex: } \\
\text { musculatura, } \\
\text { articulações, } \\
\text { equilíbrio, simetria, } \\
\text { linhas de força do } \\
\text { corpo. }\end{array}$ & $\begin{array}{l}\text { Postura (posição } \\
\text { diante do mundo); } \\
\text { afetos (sensações, } \\
\text { sentimentos); } \\
\text { predicados poéticos } \\
\text { (o gesto visto de } \\
\text { dentro) }\end{array}$ & $\begin{array}{l}\text { Desenhe uma linha } \\
\text { (fechada, aberta, } \\
\text { pontinhada, } \\
\text { tracejada, etc. - } \\
\text { mas uma única } \\
\text { linha) que } \\
\text { represente seu } \\
\text { gesto }\end{array}$ & $\begin{array}{l}\text { Se esse gesto fosse } \\
\text { uma cor, que cor } \\
\text { seria? } \\
\text { (pode ser degradê, } \\
\text { mancha, } \\
\text { sobreposição, etc.) }\end{array}$ \\
\hline
\end{tabular}

Fig. 15 - modelo para elaboração do Glossário dos meus próprios gestos. 


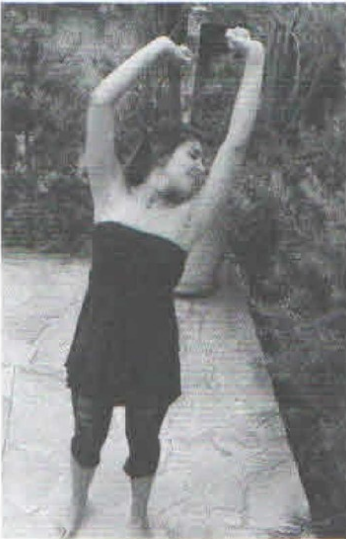

Nome do Gesto: AMM A

\begin{tabular}{|c|c|c|c|c|}
\hline O que eu faço? & O que eu sinto (1) & O que eu sinto (2) & A linha do gesto & Cor \\
\hline $\begin{array}{l}\text { O movimento tem } \\
\text { inicio nos meus pés } \\
\text { que são "plantados" } \\
\text { no chão devido ao } \\
\text { peso que deposito } \\
\text { neles. A partir dai o } \\
\text { movimento de } \\
\text { alongamento passa } \\
\text { por minhas pernas e } \\
\text { chega a coluna. } \\
\text { Lá ganha maior } \\
\text { amplitude, esticando } \\
\text { a coluna o caminho } \\
\text { segue para meus } \\
\text { braços que levantam } \\
\text { as mãos junto com a } \\
\text { cabeça na intenção de } \\
\text { subir até o ponto mais } \\
\text { alto. Nesse momento } \\
\text { a coluna mexe como } \\
\text { um espreguiçar. }\end{array}$ & $\begin{array}{l}\text { Peso na ponta } \\
\text { dos meus pés, } \\
\text { seguido de uma } \\
\text { extensão dos } \\
\text { joelhos. Quando } \\
\text { chega na coluna, } \\
\text { o gesto fica mais } \\
\text { suave, leve. } \\
\text { Minha caixa } \\
\text { torácica expande, } \\
\text { meu peito abre e } \\
\text { os braços fluem } \\
\text { para o alto com } \\
\text { leveza. } \\
\text { Se abrem } \\
\text { espaços no meu } \\
\text { corpo, tanto no } \\
\text { tórax quanto na } \\
\text { coluna e pescoço, } \\
\text { que esticam. }\end{array}$ & $\begin{array}{l}\text { O gesto parece } \\
\text { emitir luz. Como } \\
\text { se ao esticar } \\
\text { liberasse, } \\
\text { irradiasse. } \\
\text { Na maior parte } \\
\text { das vezes ele não } \\
\text { surge com a } \\
\text { intensão de } \\
\text { espreguiçar. } \\
\text { Surge em todos } \\
\text { os momentos em } \\
\text { que me sinto } \\
\text { confortável, } \\
\text { alegre, aliviada. } \\
\text { Como se } \\
\text { desprendesse um } \\
\text { sentimento ou } \\
\text { algo do tipo. } \\
\text { O modo como a } \\
\text { coluna se move } \\
\text { faz com que eu } \\
\text { sinta cada parte } \\
\text { dela. }\end{array}$ & $\because$ & \\
\hline
\end{tabular}

Fiq. 16 e 17 - "AMM A", Julia de Paula Vera (2016).

Sérgio Roclaw Basbaum, Linguagem em carne viva: corpo, percepção, linguagem (rumo a uma semântica... 
(5) Nome do Gesto: Tí

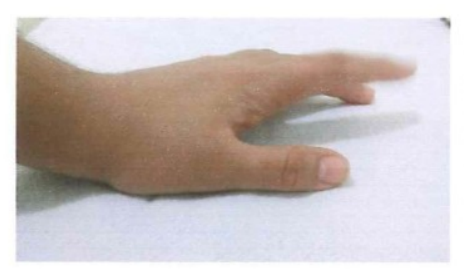

o que eu faço? Com minha mão apoiada sobre uma superfície (ex.: mesa, minha própria perna etc.), levanto e abaixo meu dedo indicador, batendo nessa superficie de modo firme e ritmado.

\section{o que eu sinto (1): Tensão nos tendões do meu braço, de modo que ela vai desde meu cotovelo até a ponta do meu dedo indicador. O impacto dele com a superficie rígida causa uma reverberação do movimento até a outra extremidade do dedo.}

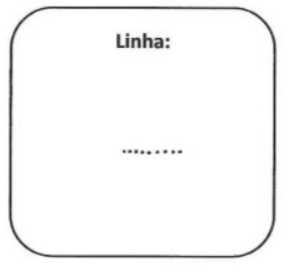

o que eu sinto (2): Nervosismo, tensão e alerta, de um modo

introspectivo, mas que todo

o mundo à volta fica mais

intenso e presente, de um

jeito "mais agudo",

Cor: Amarelo

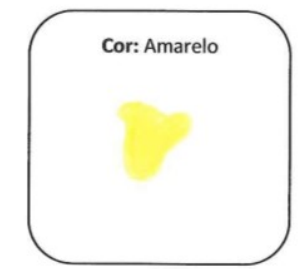

Fig. 18 - "Ti", Letícia Migliorini do Amaral (2016). 


\section{Fechando o círculo:}

Finalmente, pode-se vislumbrar um outro eixo gestual, da carnalidade do corpo à transcendência da linguagem:

$\begin{array}{ll} & <\text { gestos }> \\ \text { Corpo }>\quad<\text { Linguagem verbal }\end{array}$

(retomando a relação entre biologia e cultura, isto significa que certos gestos estão mais próximos do corpo - como coçar uma picada de mosquito -, enquanto outros, como "dar tchau", estão mais perto de se tornarem palavras)

Entretanto, os aspectos hierárquicos colapsam, como sempre, quando chegamos mais perto das coisas. Em Língua e Realidade, publicado pela primeira vez no Brasil em 1963, Vilém Flusser apresenta seu diagrama daquilo que nomeia "o cosmos da linguagem" (Fig. 19).

Neste diagrama, podemos ver que, de acordo com Flusser, a linguagem começa do nada inarticulado, silêncio inautêntico; torna-se "balbucio", em seguida "salada de palavras", e então "conversa fiada". A partir deste ponto, ingressamos na "conversação" que é, para Flusser, "criação de mundo", pois expande a realidade e cria conheci- mento. Temos, aí, dois tipos de "conversas sobre a língua": filosofia e ciência. A filosofia discute palavras como "belo", "estética", "ética", "verdade" etc.; a ciência discute palavras tais como "vida", "natureza", "universo", "realidade" etc.

Acima da ciência e da filosofia, porém, diz Flusser, temos duas outras formas de conversa, que se relacionam ao silêncio autêntico, o "nada além da língua" - aquilo que não pode ser dito. Estas formas são a "poesia", porque "arranca língua do nada"; e, finalmente, a "oração", que se dirige "ao nada além da língua". Provavelmente não há melhor definição laica do sentido da oração.

Entretanto, colocar-se em relação com um além da língua não significa lançar-se ao um céu platônico das ideias, precisamente porque, em nossa experiência encarnada, tudo retorna ao corpo. O pesquisador e iogue paulistano Danilo Patzdorf mostrou isso extraordinariamente com seus vídeos batizados Oração Corporal (Fig. 20): justamente são as torções e dobras do corpo, na busca por exprimir o inexprimível, que permitem o acesso, uma relação, ou dão uma forma expressiva e poética à mediação com aquilo que ultrapassa a dimensão da palavra, o "nada além da língua" flusseriano. 


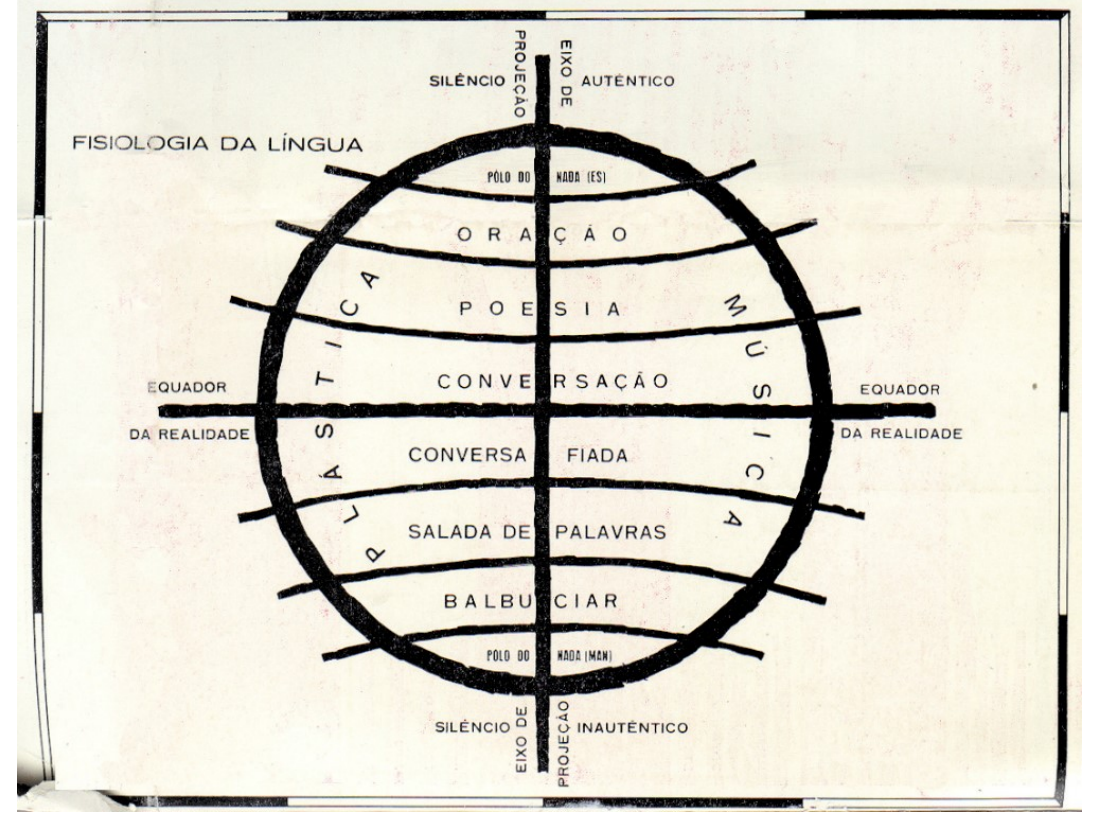

Fig. 19 - A "fisiologia da linguagem", de Vilém Flusser (1963). 


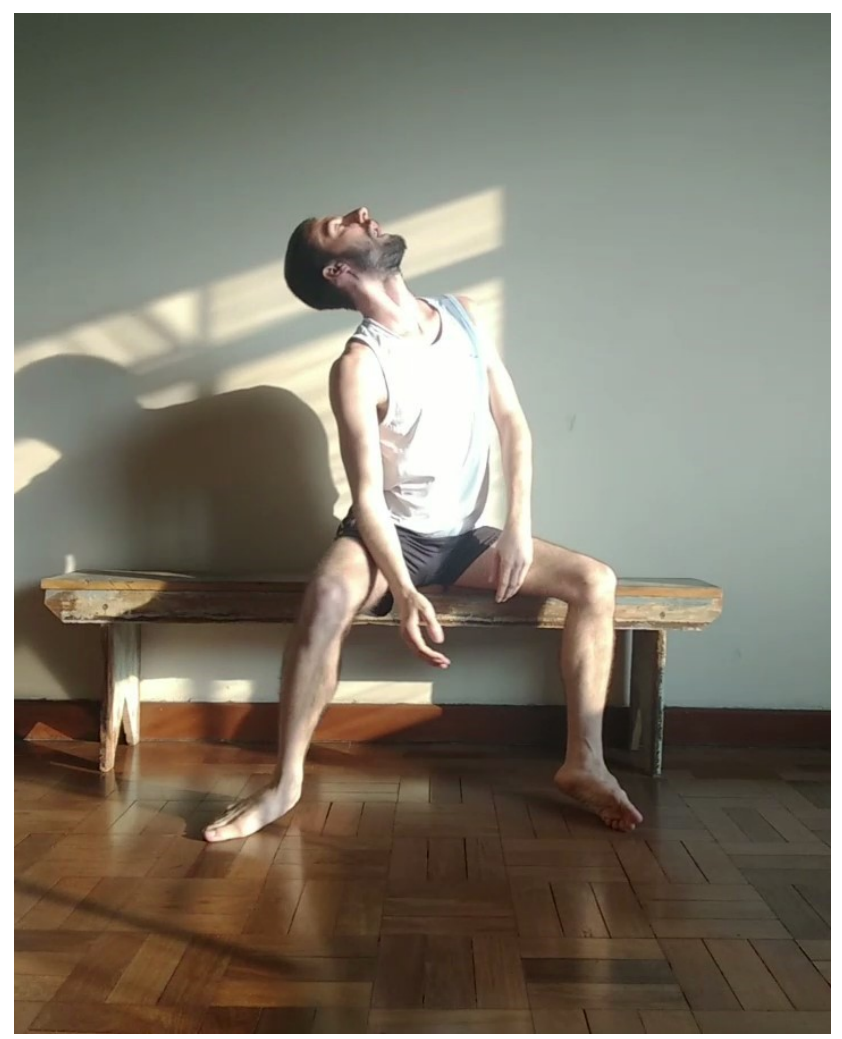

Fig. 20 - Danilo Patzdorf, Oração do Corpo (2017).

Sérgio Roclaw Basbaum, Linguagem em carne viva: corpo, percepção, linguagem (rumo a uma semântica... 
Fechamos, assim, o círculo. Fomos do corpo à linguagem, e retornamos novamente à unidade do corpo e à unidade dos sentidos.

\section{Primeiras conclusões}

Não está claro ainda até onde esse processo pode conduzir um entendimento das relações entre corpo-percepção-linguagem. O escopo da abordagem teórica e das conclusões experienciais ultrapassa os limites deste primeiro esforço de formalização, e merece ainda meIhor desenvolvimento. Entretanto, parece claro que não apenas se abrem aqui janelas para interpretar o problema da semântica em termos de seu enraizamento no corpo, mas que, se queremos compreender a semântica, sempre acabaremos retornando ao corpo e à sua unidade sensória. Como diz MerleauPonty, a sinestesia é a regra - a base de todo o significado. Além disso, se o gesto está a meio caminho entre o corpo e a linguagem verbal que ele articula, a estratégia de elaborar uma semântica dos gestos a partir de predicados heterossemióticos e intersemióticos permite manter, no plano do gesto, uma abertura semântica que é característica da linguagem natural, a que o gesto deverá conduzir [Maturana (2002, p. 37): "o verdadeiro segredo da linguagem: o apontar"].
No primeiro curso (2015), não documentado, durante o workshop conduzido por Julia Salém e Juliana Gennari, tive a impressão de assistir a um rascunho das origens da linguagem: gestos partilhando coisas percebidas, que se tornam coisas intersubjetivas e então gestos intersubjetivos, daí linguagem, e então cultura.

No segundo curso (2016), ao qual pertencem as imagens que ilustram o artigo, o que se observou por meio de estratégias que resultam na elaboração do Glossário foi um engajamento excepcional dos alunos e um grande aprofundamento da percepção de si, dos próprios gestos e da habilidade de notar, observar e atribuir sentido aos mínimos gestos dos colegas.

A metodologia proposta com o uso do glossário, ainda que incipiente, foi suficientemente simples para que a/o estudante pudesse se engajar nessa observação dos próprios gestos e, ao mesmo tempo, ofereceu um modo de circunscrever uma dimensão multisensorial e heterossemiótica à potência do corpo de comunicar seu mundo aos outros, conectando sentidos, corpo, afetos, formas abstratas e pseudo-palavras a cada gesto observado. 
Essa metodologia, ao mesmo tempo aberta e precisa, foi replicada na pós-graduação, no Teatro Escola Célia Helena (2017), com um glossário reduzido a cinco gestos, e resultados, porém, igualmente intensos. No início de 2018, Camila Venturelli, Julia Salém e eu conduzimos um curso no Centro de Referência da Dança, em São Paulo, onde muitas destas questões foram novamente retomadas, sempre com resultados positivos.

Há agora o desafio de encontrar, nos próximos anos, oportunidades de continuidade, buscando estratégias para melhorar a metodologia e o processo de documentação do trabalho, sem perder seu caráter profundamente experiencial. Outras ferramentas incorporadas, como, por exemplo, o Jogo dos Gestos, contribuíram ao engajamento. Apostas teóricas, além da Fenomenologia merleau-pontyana e os trabalhos recentes em cognição situada e percepção enativa, são a semântica do corpo de Ruthrof e as pesquisas em neurociência de Gyorgy Buz-saki, das quais pouco pudemos tratar aqui. TrabaIhos extraordinários como o livro da coreógrafa Dani Lima (2013), que conheci apenas ao final do percurso aqui descrito, e o livro Gestos de Vilém Flusser (em suas várias versões não coincidentes), que esteve no horizonte dos cursos são também referências importantes no radar. Outras referências vêm sendo descobertas, mas são posteriores ao processo descrito no artigo. Procurou-se delinear aqui um caminho para propor novos modos de interpretar esses dados e resultados em termos de uma teoria das relações entre gesto e significado, na busca de uma semântica do gesto que seja ao mesmo tempo aberta, portanto rica, e, no entanto, precisa, circunscrevendo um domínio de sentido em uma chave sinestésica.

sb.

São Paulo, Los Angeles, Alcalá La Real, São Paulo, novembro 2017-19

O autor agradece as parcerias das artistas Julia Salem, Juliana Gennari e Camila Venturelli, e às alunas e alunos que deram oportunidade ao desenvolvimento desse trabalho em seus diferentes estágios; especialmente, Leticia Migliorini e Julia de Paula, por me permitirem expor trechos de seus belos glossários, e Danilo Patzdorf pelas imagens de seu vídeo. E aos organizadores dos eventos em que foi apresentado e discutido durante os anos de 2017-18, especialmente Carol Steen, Dr. Sean A. Day, Dra. Maria José de Córdoba e Dra. Dina Riccó, e os demais membros da American Synesthesia Association (ASA), da International Association for Synesthetes, Artists and Scientists (IASAS) e da Fundación Artecittá. No Brasil, à Dra. Rosangella Leote, à Dra. Hosana Celeste e demais membros do Grupo Internacional e Interinstitucional de Pesquisa em Convergências entre Arte, $\mathrm{Ci}$ ência e Tecnologia (Giip).

Sérgio Roclaw Basbaum, Linguagem em carne viva: corpo, percepção, linguagem (rumo a uma semântica... 


\section{Notas}

${ }^{1} \mathrm{O}$ processo que é objeto deste artigo foi apresentado em alguns encontros internacionais (American Synesthesia Association, 12th National Conference, 2017, em Harvard, Boston; 1st IASAS Symposium, 2017, UCLA, Los Angeles; VI Congresso Internacional de Sinestesia, Ciencia y Arte, 2018, Alcalá La Real), e uma vez no Brasil (Ciclo Arte e Neurociência, 8/11/2018, UNESP, São Paulo) . A oportunidade de publicá-lo permite que se possa partilhar seus resultados, enquanto se constrói um caminho de continuidade às ricas possibilidades de pesquisa que se abrem aqui.

${ }^{2}$ Instaura_ação foi contemplado no Edital para Projetos de Dança Site-Specific do Centro Cultural São Paulo, em 2014. 0 autor assinou o projeto de som deste trabalho, que incluía três diferentes roteiros sonoros, experienciados individualmente pelo público participante.

${ }^{3}$ Devo a Camila Venturelli a incorporação da ideia de "relevo" à definição do modo de ser da percepção. Essa palavra tão simples consegue manter a distinção figura-fundo, que me dá "coisas", sem perder o caráter global da experiência, em que figura e fundo são partes de um mesmo contexto.

${ }^{4}$ O neologismo "enminded" body, ou "corpo com mente", que inverte o conceito de embodied mind não me parece ter tradução à altura em português. A rigor, embodied mind, que traduzi aqui como "mente encarnada", também não tem uma tradução satisfatória para o português. Aliás, do mesmo modo, o conceito enactive perception vem, na minha opinião, sendo traduzido de modo equivocado. A busca de manter a correspondência com o original em inglês faz perder um aspecto muito importante do conceito: enact, em inglês, quer dizer "encenar", ou seja, a percepção encena o mundo das nossas condutas. A tradução por encenativa, me parece, deixaria muito mais claro aquilo que propõe o conceito.

\section{Referências}

AGAMBEM, Giorgio. Notas sobre o gesto. Artefilosofia. Ouro Preto, n. 4, p. 09-14, 2008.

BASBAUM, Sérgio. O primado da percepção e suas consequências no ambiente midiático. São Paulo: Intermeios/FAPESP, 2016.

BASBAUM, Sérgio. Do ponto de vista ao ponto de experiência. Trama: Indústria Criativa em Revista. Dossiê: Paisagens sonoras midiáticas, ano 3, v. 5, p. 220-7, 2017.

BASBAUM, Sérgio. Esboço de uma teoria das relações entre percepção e linguagem, sob a determinação do sentido. In QUARESMA, Alexandre (Ed.). Artificial Intelligences Essays on Inorganic and Nonbiological Systems. Madrid: Global Knowledge Academics, 2018a.

BASBAUM, Sérgio. Tudo isso é do baralho: tecnoestese e infocognição (da ordem e dos predicados dos acoplamentos na circunstância contemporânea). Texto Digital, Florianópolis, v. 14, n. 1, p. 6-25, jan./jun. 2018b.

BUZSAKI, Gyorgy. Rhythms of the Brain. Oxford: Oxford University Press, 2011.

CLASSEN, Constance. Worlds of Sense: Exploring the Senses in History and Across Cultures. Londres: Routledge, 1993.

CYTOWIC, Richard. Synesthesia: phenomenology and neuropsychology. In BARONCOHEN, Simon; HARRISON, John. Synesthesia: Classic and Contemporary Readings. Oxford: Blackwell Publishers, 1997. 
DUPUY, Jean-Pierre. Nas origens da ciência cognitiva. São Paulo: UNESP, 1996.

FELD, Steven. Places Sensed, Sensed Places. In HOWES, David (Ed.). Empire of the Senses - the Sensual Culture Reader. Oxford: Berg, 2005.

FLUSSER, Vilém. Texto/imagem enquanto dinâmica do Ocidente. Cadernos Rioarte, n. 5, 1986.

FLUSSER, Vilém. Gestos. São Paulo: Annablume, 2014.

FLUSSER, Vilém. Los gestos. Barcelona: Editorial Herder, 1994.

HOWES, David. Sensual Relations - Engaging the Senses in Culture and Sensual Theory. Ann Arbor: Michigan University Press, 2003.

INGOLD, Tim. The Perception of the Environment - Essays on Livelyhood, Dwelling and Skills. Londres: Routledge, 2000.

LIMA, Dani. Gesto - práticas e discursos. Rio de Janeiro: Cobogó, 2013.

MARKS, Lawrence E. The Unity of the Senses - Interrelations Among the Modalities. Nova York: Academic Press, 1978.

MATURANA, Humberto. Ontologia da realidade. Belo Horizonte: UFMG, 2002.

McLUHAN, Marshall. Essential McLuhan (editado por E. McLuhan e F. Zingrone). Concord: BasicBooks, 1995.
MERLEAU-PONTY, Maurice. A prosa do mundo. São Paulo: Cosac \& Naify, 2002.

MERLEAU-PONTY, Maurice. Fenomenologia da percepção (tradução de Carlos Alberto Ribeiro de Moura). São Paulo: Martins Fontes, 1994.

NOE, Alva. Action in Perception. Cambridge: MIT Press, 2004.

QUARESMA, Alexandre (Ed.). Artificial Intelligences Essays on Inorganic and Nonbiological Systems. Madrid: Global Knowledge Academics, 2018.

RAMACHANDRAN, V. S.; HUBBARD, Edward. Synaesthesia - a Window to Perception Thought and Language. Journal of Consciousness Studies, v. 8, n. 12, p. 3-34, 2001.

RUTHROF, Horst. Semantics and the Body Meaning from Frege to the Post Modern. Toronto: Toronto University Press, 1997.

VARELA, Francisco J.; THOMPSON, Evan; ROSCH, Eleanor. The Embodied Mind, Cognitive Science and Human Experience.

Cambridge: MIT Press, 1991.

\section{Filmografia}

DEREN, Maya. Ritual in Transfigured Time (1946).

GODARD, Jean-Luc. Histoire(s) du Cinema, 2A: Fatale Beauté (1998).

Sérgio Roclaw Basbaum, Linguagem em carne viva: corpo, percepção, linguagem (rumo a uma semântica. 